\title{
Learning "What" and "How" in a Human Motor Task
}

\author{
Vernon Brooks, ${ }^{1,5}$ Frank Hilperath, ${ }^{2}$ Martin Brooks, ${ }^{3}$ Hans-Georg Ross, ${ }^{4}$ and \\ Hans-Joachim Freund ${ }^{2}$ \\ ${ }^{1}$ Department of Physiology \\ University of Western Ontario \\ London, Ontario N6A 5C1, Canada \\ ${ }^{2}$ Department of Neurology \\ Heinrich-Heine-University Düsseldorf \\ 40225 Düsseldorf, Germany \\ ${ }^{3}$ Institute for Information Technology \\ National Research Council of Canada \\ Ottawa, Ontario, K1A 0R6, Canada \\ ${ }^{4}$ Department of Physiology \\ Heinrich-Heine-University Düsseldorf \\ 40225 Düsseldorf, Germany
}

\begin{abstract}
We studied the development of implicit and of verbally declared knowledge for normal human subjects who learned an unfamiliar motor task in one learning session. The exploratory nature of motor learning and a special period for optimizing skill were followed in real time. Subjects understood the goal for task success, but they had to learn a motor strategy of what pattern of serial movements to make and the tactics of bow much to scale their amplitudes and timing. We compared the time course for acquiring tactical skill with that for acquiring knowledge of strategy and of tactics, and their necessary cues. Implicit and declarative knowledge were distinguished from one another by correlating subjects' verbal self-reports with movement kinematics and their results. Implicit generation of the correct strategy and of the tactics developed in an exploratory manner from the beginning of the learning session. Implicit strategy learning soon gave way to conscious efforts, but tactical learning remained implicit until its first unambiguous verbal declaration
\end{abstract}

5Corresponding author. (with one exception). First strategy declarations were voiced before those for tactics, during trial-and-error learning that did not require task success, and referred to reversing the direction of hand movements (one exception). In contrast, first declarations of tactics almost always required actual or imminent success, referred to when direction was to be reversed, and it was achieved near the top of a sigmoid learning curve that rose to tactical skill (with one exception). During the sigmoid rise, movement amplitudes and timing were optimized in a distinct manner, although tactics usually adapted thereafter to movements of more moderate speed that could still be successful.

\section{Introduction}

The emergence of various views of motor learning that are based on different methods provided the impetus for the present work. For instance, traditional studies, such as serial reaction time tests, sample selected moments during task execution, whereas kinematic, electrophysiologi$\mathrm{cal}$, and some other analyses sample in real time. By combining methods one can ... "capture many of the dynamic qualities of the stages of motor skill acquisition" ... [where] ... "skill is a reflection of

LEARNING \& MEMORY 2:225-242 @ 1995 by Cold Spring Harbor Laboratory Press ISSN1072-0502/95 \$5.00

$$
\begin{array}{lllllllllllllllll}
\hline & E & A & R & N & I & N & G & \begin{array}{l}
\text { Q } \\
225
\end{array} & M & E & M & O & R & Y
\end{array}
$$


a dynamic exploratory activity" (Newell 1991, p. 233 , italics added). Also, there are growing physiological and pathological analyses of the neural systems that support declarative, as opposed to nondeclarative knowledge, and of systems supporting motor strategies as opposed to motor tactics. Analyses of these neural systems become more dynamic when they are based on functional magnetic resonance imaging that can sample many times per second. Imaging of structures that support these diverse aspects of motor learning calls for methods of distinguishing the learning components from one another as much as possible, in real time. In this paper we present such a method with a paradigm that is based on rate control. The results obtained give a first glimpse of the exploratory activity of learning a motor strategy and its tactical skills in real time. We correlated subjects' verbal self-reports about understanding their performance of an unfamiliar task with records of their movements and what they produced.

Specifically, we followed the development of strategic and tactical declarative knowledge, as well as of motor skill, in real time during the learning session with respect to two measures: (1) When did knowledge of strategy and tactics become verbal during the learning session; and (2) what cues were needed for these two kinds of verbal declarative knowledge and for development of skill. As far as we know, the paradigm, combination of methods, and the results obtained with them are new.

For this presentation, we define motor strategy as the choice of what pattern of serial movements to make and tactics as bow much to scale movement amplitudes and timing. These definitions fit those of Newell (1985), strategies correspond to "coordination" which constrains movement variables, and tactics correspond to "control", which assigns values to those variables. Motor strategies are distinct from the overall behavioral goal and also from the plan to accomplish a particular event or series of events. Passingham (1993) also distinguishes between "plans" as specification of appropriate actions and "strategy" as a series of events. In this study subjects understood the behavioral goal because they acknowledged the explanation given to them before they began the learning session. The term skill denotes optimal use of tactics (e.g., Newell 1985; Passingham 1993). This depends on the progress of learning within the first session, on which we focus here and on further practice thereafter. Therefore, we use the term skill to denote the optimal use of tactics under the circumstances of the moment.

The term declarative is used in the sense of what can be declared or brought to mind as a proposition or an image (Squire and Zola-Morgan 1988). It is expressed (e.g., verbally in this study) by deliberate recollection of information that is bound to a particular time and context. "Nondeclarative" knowledge is expressed by behavior that demonstrates previous exposure to a task that has resulted in improved performance but without the subject having conscious recollection of that previous exposure (Zola-Morgan and Squire 1993). Because we could not be certain of the subjects' conscious recollections (cf. Merikle and Reingold 1992), we refer to knowledge that was demonstrated by the generation of appropriate movements, but not declared verbally, by the older term "implicit" (Nissen and Bullemer 1987). In their reaction time tasks, which exclude verbal self-reports, implicit knowledge is demonstrated by subjects' shortening reaction times for pressing particular keys in response to a series of targets presented in a repeating pattern, despite the inability of these individuals to make their knowledge of the series explicit by generating predictive selections of the target to be displayed in the following trial. We can follow implicit and declarative learning of strategy and of tactics in real time without having to generate interposed manual demonstrations because we combine analyses of movement kinematics and the resulting task performance with verbal self-reports.

In our task, the subjects' goal was to guide a display cursor into a target. The task forced subjects to chose an unusual motor strategy because they had to gain control over an apparently runaway cursor (that was, unbeknownst to them, guided by rate control, in which cursor velocity is modulated by hand position rather than hand velocity; (c.f. Kim et al. 1987). The correct motor strategy was to make successive, oppositely directed hand movements by which to govern the rise and fall of cursor velocity (Fig. 1). This pattern of serial movements is different from producing the same cursor path for the same behavioral goal as would be used for computer drawing when single hand movements are the correct, usual strategy (with position control where cursor position is directly proportional to hand position).

We found, with very few exceptions, that strategy declarations were voiced first before those for tactics and that they did not require task

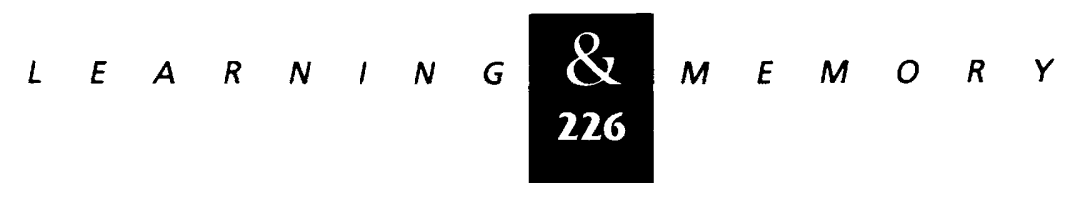



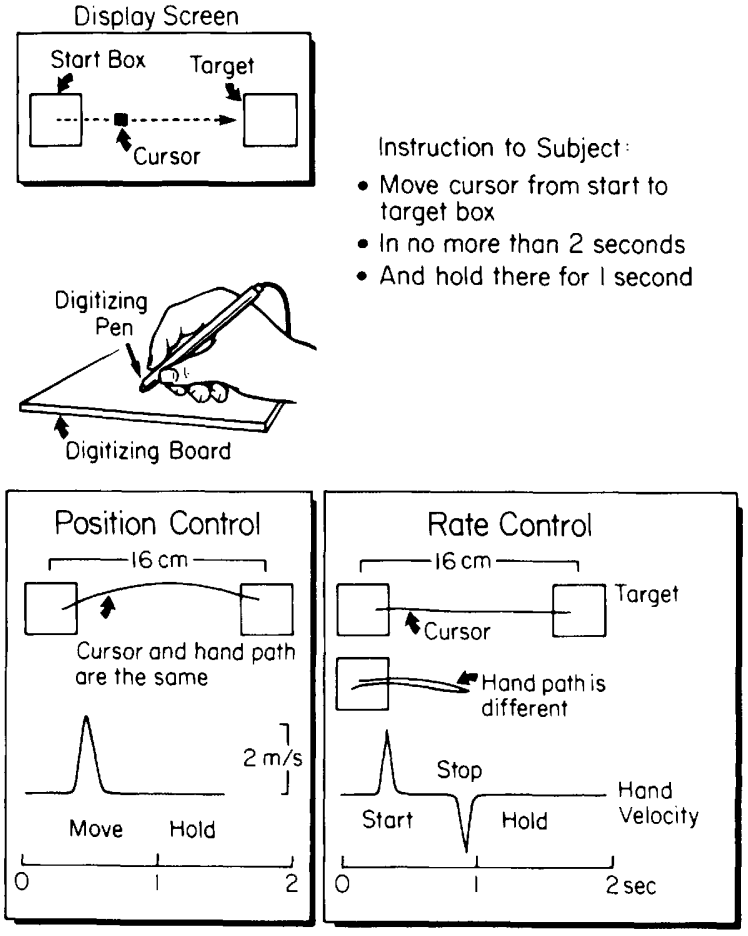

Figure 1: Explanation of test method and display. (Top) Step-tracking paradigm for guiding a cursor on a display screen from start to target box by moving a hand-held digitizing pen on a digitizing board. (Right) Summary of task instructions. (Bottom) Position control (left) and rate control (right). Tracings show planar hand and cursor paths and hand velocity profiles made by a proficient, overtrained subject who used well-programmed movements, and completed trials within $2 \mathrm{sec}$ (the acceptable limit was $3 \mathrm{sec}$, as in Fig. 5A, during learning). Timer intervals were $1 \mathrm{sec}$; length of hand path with position control was $\sim 16 \mathrm{~cm}$; with rate control, stop and start movements were 7.8 and $7.1 \mathrm{~cm}$; velocity calibration was $2 \mathrm{~m} / \mathrm{sec}$; distance between centers of start and target box was $16 \mathrm{~cm}$.

success but only exploratory performance. First strategy declarations referred to reversing the direction of hand movements, and those of tactics to when this reversal had to be made. First tactical declarations most often required actual or imminent success that was achieved near the top of a sigmoid learning curve to tactical skill. During this well-defined period, movement amplitudes and timing were optimized in a distinct manner. Although the sigmoid rise had similar durations for all subjects, its onset after the first verbal declaration of strategy knowledge varied widely between subjects.

The results are discussed in relation to other studies and are considered briefly with regard to possible underlying neural systems. Parts of this work have been reported in abstract form (Brooks et al. 1992, 1994).

\section{Materials and Methods}

\section{SUBJECTS}

Tests were made on 25 normal volunteer subjects recruited from the academic environment of the Heinrich-Heine-University Düsseldorf and the Psychosoziale Hilfe Krefeld, who gave informed consent. The subjects enjoyed it as a challenging computer game. Subjects were $20-43$ years of age and had no histories of previous neurological disorders. All were right-handed and were tested with the right hand, and none knew the learning task, at least explicitly by name, before the test sessions.

\section{TEST AND APPARATUS}

Figure 1 illustrates the method. Subjects were seated at a table with a horizontal digitizing board within easy reach and observed a vertical display screen $(52 \times 38 \mathrm{~cm}) \sim 70 \mathrm{~cm}$ in front of them. They moved a pen on a digitizing board (Digipad, type 5A, GTCO Corp., Columbia, MD.; 40 pixels/ $\mathrm{mm}$ ) to guide a cursor on a display screen from a start box to a target box, using mostly wrist movements but the elbow and shoulder were also involved to a minor extent. Subjects looked at the screen to see the cursor movements created by their hand movements on the board. The distance between start and target boxes on the display on screen was $16 \mathrm{~cm}$ between box centers. Boxes were $4 \times 4 \mathrm{~cm}$, with borders of $1.4 \mathrm{~mm}$ width; and the cursor was a filled red square with sides of $8.13 \mathrm{~mm}$.

\section{PARADIGM}

Subjects were given written general instructions before the learning session, including "... to move as rapidly and accurately as possible." They were alerted that the cursor would move in an unexpected manner but without any particulars. Before beginning, they were reminded that the task goal was to land the cursor in target within 2 sec and then to hold it there for $1 \mathrm{sec}$. Their ac-

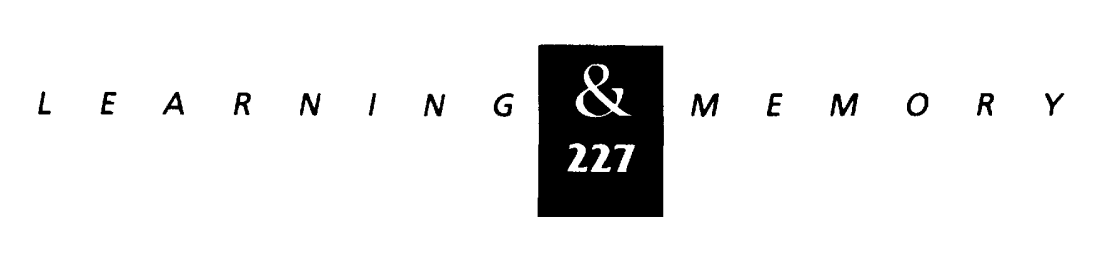




\section{Brooks et al.}

knowledgment ensured that they had understood the goal. In an initial series of 10 "silent" subjects, all further conversation was stopped because pre. vious tests had shown that this scattered the learning data, but we accepted that in the main study of eight "talking" subjects who were asked to verbally declare their solutions of the task during the session, both before it began and by prompting during its progress. All comments were recorded on the voice video channel in synchrony with the records of the display screen that also showed the trial numbers. Subjects' attention, readiness to talk, and clarity of expression were graded collectively as "verbal responsiveness" from grade A down to $C$ after repeated listening to the tape (Table 1 , column 10). Attention and verbal facility were dis- tinguished from one another roughly by the subjects' readiness and adaptness at giving self-reports. Grade $\mathrm{C}$ was applied when they had to be prompted to speak more than roughly every 20 trials. Comparison of subjects' verbal comments with their records of hand and cursor movements established whether knowledge was declarative or implicit.

Each trial began with the appearance of the start box on the left side of the screen. To prevent data collection from being started by unintended movements ( $<1.5 \mathrm{~mm}$ ), a steady tone warned subjects to hold the cursor steady for $1.5 \mathrm{sec}$ in the start box ( $2.25 \mathrm{~mm}^{2}$ on the digitizing board). Data collection in a trial began with the appearance of the target box on the right side of the screen,

Table 1: Sequence of kinematic events and of declarations in learning the rate-control task

\begin{tabular}{|c|c|c|c|c|c|c|c|c|c|}
\hline 1 & 2 & 3 & 4 & 5 & 6 & 7 & 8 & 9 & 10 \\
\hline \multirow[b]{3}{*}{ Subject } & \multirow{3}{*}{$\begin{array}{l}\text { Initial } \\
\text { search } \\
\text { (no. of } \\
\text { trials) }\end{array}$} & \multirow{2}{*}{\multicolumn{2}{|c|}{$\begin{array}{l}\text { Sigmoid } \\
\text { rise }\end{array}$}} & \multirow{3}{*}{$\begin{array}{c}\text { Task } \\
\text { success } \\
\text { (first at } \\
\text { trial) }\end{array}$} & \multicolumn{4}{|c|}{$\begin{array}{c}\text { Declarations of insight } \\
\text { during test session }\end{array}$} & \multirow{3}{*}{$\begin{array}{c}\text { Verbal } \\
\text { and } \\
\text { attention } \\
\text { grade }\end{array}$} \\
\hline & & & & & & tegy & & tics & \\
\hline & & $\begin{array}{l}\text { (no. of } \\
\text { trials) }\end{array}$ & $\begin{array}{l}\text { (ends at } \\
\text { trial) }\end{array}$ & & $\begin{array}{l}\text { (first at } \\
\text { trial) }\end{array}$ & $\begin{array}{l}\text { (confirm } \\
\text { at trial) }\end{array}$ & $\begin{array}{l}\text { (first at } \\
\text { trial) }\end{array}$ & $\begin{array}{l}\text { (confirm } \\
\text { at trial) }\end{array}$ & \\
\hline \multicolumn{10}{|l|}{ Talking } \\
\hline $\mathrm{Gi}^{*}(\mathrm{M})$ & N.A. & 71 & 71 & 10 & 9 & 29,81 & 63 & 70 & A \\
\hline $\mathrm{Mo}^{*}(\mathrm{~F})$ & N.A. & 54 & 54 & 14 & 14 & 46 & 166 & & C \\
\hline $\mathrm{Ma}^{*}(\mathrm{M})$ & N.A. & 93 & 93 & 23 & 18 & 46 & 18 & 57,75 & B \\
\hline $\mathrm{Ju}(\mathrm{M})$ & 12 & 5 & 17 & 17 & 7 & 18 & 135 & 140 & A \\
\hline Bo $(F)$ & 16 & 34 & 50 & 45 & 19 & 45,60 & 42 & 54 & C \\
\hline $\mathrm{Ge}(\mathrm{M})$ & 43 & 19 & 62 & 58 & 15 & 59 & & & B \\
\hline Le $(M)$ & 55 & 8 & 63 & 56 & 24 & 59 & 59 & 98,151 & B \\
\hline$S c(M)$ & 136 & 6 & 142 & 50 & 51 & 87 & 56 & 63,140 & C \\
\hline \multicolumn{10}{|l|}{ Silent } \\
\hline$A^{*}(F)$ & N.A. & N.A. & N.A. & 6 & & & & & \\
\hline $\mathrm{B}^{*}(\mathrm{M})$ & N.A. & 53 & 53 & 22 & & & & & \\
\hline$C^{*}(F)$ & N.A. & 47 & 47 & 20 & & & & & \\
\hline$D^{*}(M)$ & N.A. & 45 & 45 & 22 & & & & & \\
\hline$E(F)$ & 27 & 5 & 32 & 32 & & & & & \\
\hline$F(F)$ & 27 & 29 & 56 & 44 & & & & & \\
\hline$G(M)$ & 37 & 5 & 42 & 48 & & & & & \\
\hline$H^{\#}(F)$ & N.A. & N.A. & N.A. & 96 & & & & & \\
\hline$I(M)$ & 75 & 21 & 96 & 90 & & & & & \\
\hline$J(M)$ & 96 & 21 & 117 & 116 & & & & & \\
\hline
\end{tabular}

Subjects (column 1) ordered by increasing duration of initial trial-and-error search (column 2), i.e., the time before the sigmoid rise of the learning curves (columns 3 and 4). (Column 5) First task success. Declarations of insight during the test session about strategy (columns 6 and 7) and about tactical implementation (columns 8 and 9). (Column 10) Grade combining attention and verbal facility. (N.A.) Not applicable; $\left(^{*}\right)$ nonsearch subjects; $\left(^{*}\right)$ sigmoid could not be fitted meaningfully; (F) female; (M) male. Data are from Figs. 2 and 3.

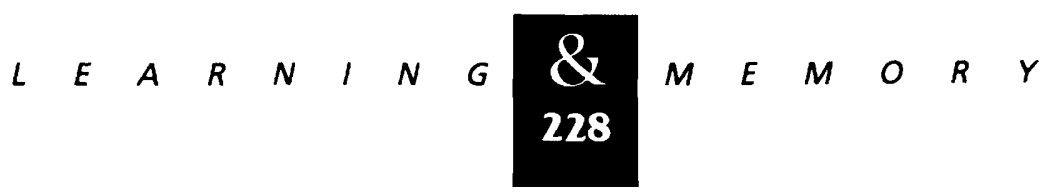


accompanied by an auditory Go! signal to move the cursor toward the target. The presence of the cursor in target was signaled by a tone. A session of 200 trials took $25 \mathrm{~min}$, on average, and caused neither visible stress or anxiety nor reports of such by the subjects.

\section{TIMING REQUIREMENTS}

Timing requirements for the trials were the completion of all hand movements within $2 \mathrm{sec}$ after the Go! signal, and a cursor dwell time in target of 1 sec before the trial was counted as complete by the paradigm program. "Move times" of $2 \mathrm{sec}$ were sufficiently long for successive movements of moderate speed, which made subjects stress accuracy more than speed (c.f. Gottlieb et al. 1989). Data pairs of $x, y$ data were sampled at $50 \mathrm{~Hz}$ by a computer (Atari ST), but trial durations could differ because subjects were able to correct cursor trajectories. Corrective return moves into target had to be completed within an unused part of the 2-sec move time but could not exceed the sums of maximum move times and minimum dwell times in target. This was managed by two independent timers for total move times and dwell times, respectively, the sums of which determined the trial duration. Trial durations could therefore differ according to performance. Trial completion was followed by disappearance of the display, and after a momentary pause, another trial began with the same display and requirements. All data were time comparable within the limits of the sampling rate. (Only subjects Le, Ma, and Sc had slightly different settings: Dwell times were shortened from 1 to $0.5 \mathrm{sec}$, target distance was shortened from 16 to $12 \mathrm{~cm}$, and target size from 4 to $3 \mathrm{~cm}$, preserving the same spatial dimensions.)

\section{DATA BASE AND ANALYSIS}

\section{DEFINITIONS FOR MEASUREMENTS}

The data base consisted of all hand (i.e., pen) movements in the $x$ and $y$ plane of the digitizing board during each trial, without exclusions or adjustments. Initial cursor positions relative to the target were horizontal, that is, the target lay in the positive $x$ direction from the cursor in screen co- ordinates. Hand velocity in the positive $x$ direction in Digipad coordinates caused cursor acceleration in the positive $x$ direction of screen coordinates. Movement amplitudes in the planar work space were obtained by integrating the recorded planar velocities. Starting from the initial position, hand velocity with a positive $x$ or $y$ component caused the cursor to accelerate in the horizontal direction of the target (although the vertical acceleration component might not be toward the target), and hand velocity with a negative $x$ or $y$ component caused cursor acceleration in the horizontal direction of its initial position. Sample points were thus classified as "start" if their $x$ component was greater than the previous point, and as "stop" otherwise. Displacement between successive sample points was calculated with the Euclidean metric (square root of the sum of squares of the component differences).

Task performance was followed by the scaling ratio (ssr) of movement amplitudes directed toward the target (start) and those back toward the starting point (stop) for each trial. Practically all trials contained more than one pair of start and stop movements, which were taken into account because the ssr value for any one trial was the ratio of the sum of all start movements (over all start sample points, of the displacement between that point and the previous point), and the equivalent sum for all stop movements in that trial. Trials could be unsuccessful despite ssr values near one because of poor timing. Learning could thus be measured from ssr values without going into the details of move and dwell times (although all were examined in printouts of the velocity profiles and their scaling, calculated as described above).

Plots of the sequential ssr values in a learning session were scattered around S-shaped, sigmoid learning curves. It was therefore decided to fit the data robustly with sigmoid curves, whose upsweep reflects the rise of competent tactical performance with the correct strategy.

\section{ROBUST STATISTICS}

A two-parameter sigmoid model was fitted robustly to the sequential ssr values of each subject. Robust statistics differ from traditional statistical models by classifying data points as "inliers" or "outliers" and rejecting all outliers. The least median squared method was used for robust fitting of sigmoids to the ssr sequences, by way of trans-

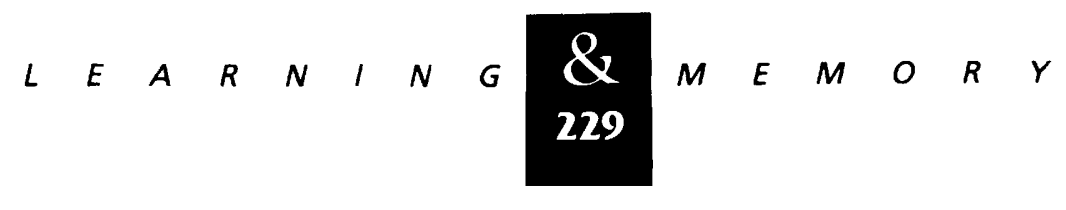


forming the sigmoid to a robustly fitted line. That line was used to divide the data into inliers and outliers. Inliers and outliers were classified by testing the ratio of the distance of each datum to the fitted line with the median distance of the data to the line. If the ratio was $<2.5$ then the datum was an inlier; otherwise it was an outlier. A linear regression line was fitted to the inliers (for details, see Rousseeuw and Leroy 1987). Our application of the method to sigmoid curves is new. The general form of a sigmoid curve, where $z$ varies over the real numbers, is

$$
f(z)=A_{\min }+\frac{A_{\max }}{1+\exp (-(z-\tau) / \sigma)}
$$

where $A_{\min }$ and $A_{\max }$ are the minimum and maximum values, $\tau$ is the $z$ value at which the sigmoid is centered, and $\sigma$ is a scaling parameter that determines the sigmoid's slope at $z=\tau$. The sigmoid can be transformed to a line with slope $1 / \sigma$ and abscissa $\tau / \sigma$ according to the equation $(z-\tau) /$ $\sigma=-\ln (f(z)-1)$. The data were so transformed, and every ssr value $d$ transformed to the new value $d^{*}=-\ln (d-1) T$. The sequence of transformed values $d^{*}$ was then robustly fitted with a line, the slope and abscissa of which give the sigmoid parameters $\sigma$ and $\tau$. The two-parameter sigmoid model used $A_{\text {min }}=0$, representing subjects with no experience, and fitted $A_{\max }$ by analysis of the average and variance of the final segment of the data. The learning curves were considered to begin with the first trial for all subjects. The points $\max (0, \tau-5 \times \sigma)$ and $\tau+5 \times \sigma$ define the beginning and end of the sigmoid rise; they are the last point, within computer precision, where the sigmoid is zero, and the first point, where the sigmoid attains its maximum value (see Table 1, columns 3 and 4).

\section{Results}

\section{TASK PERFORMANCE}

The subjects' accomplishments during the learning session are summarized in Figure 2, which indicates the main landmarks of their task performance. How well the correct strategy was used in each trial is plotted as the ratio of amplitudes of the oppositely directed movements toward the target (start) and those back towards the starting point (stop). That ssr scaling ratio rose consistently toward unity along a robustly fitted sigmoid, as tactics became sufficiently competent to gain repeated task success (see Materials and Methods). The first three subjects in Figure 2 began the session with implicit knowledge, as witnessed by an ongoing sigmoid rise of the scaling ratio. In contrast, the five other subjects began their session with trial-and-error search for the correct strategy and tactics, witnessed by variously scattered ssr values before onset of the sigmoid rise. The first three are referred to as "nonsearch" subjects, and the other five as "search" subjects. The sigmoid rise of searchers began after search periods of 12-55 trials (and for subject Sc after 136 trials), which included scattered tryouts of raising ssr values, and was completed in 5-34 trials (average 14.4). In contrast, the sigmoid rise of nonsearchers was ongoing in the first trial of the learning session, that is, it began at virtual zero values before the session, and it was completed more slowly, in 54-93 trials (average 72.67). This difference between searchers and nonsearchers is

Figure 2: Learning curves of eight subjects whose comments were recorded during the session, ordered by increasing durations of initial trial-and-error search. Curves of these talking subjects plot the scaling ratio of stop/start movement amplitudes (ssr; ordinate) against successive trials (abscissa). Robustly fitted sigmoid curves are superimposed on unsuccessful ( $\mathbf{\square}$ ) and successful ( $\square$ ) trials. The first three subjects began consistent scaling along a sigmoid rise without any preceding trial-and-error search. Upward solid and open arrows indicate first declarations of strategy and tactical insight. Declarations are listed with trial numbers (see Table 1). $\left(\mathrm{Gi}^{*}\right)$ Trial 9, "You have to pull back, it's like a rubber band"; trial 63, "You have to be careful when you turn around." (Mo*) Trial 14, "have to reverse direction"; trial 166, " always go the same distance." (Ma*) Trial 18, "I reverse as soon as I am close to the target." (Ju) Trial 7, "Aha! cannot alter direction without braking first"; trial 135, "must brake early enough." (Bo) Trial 19, "Aha! I turn on the way to the target"; trial 42, "have to hold it long enough in target"; (Ge) trial 15, "have to brake and reverse"; (Le) trial 24, "I go forward and then reverse"; trial 59, "I brake when in target to manage within $2 \mathrm{sec}^{\prime \prime} ;(\mathrm{Sc})$ trial 51 , "Aha! You have to reverse"; trial 56, "have to move within the right time and then brake."

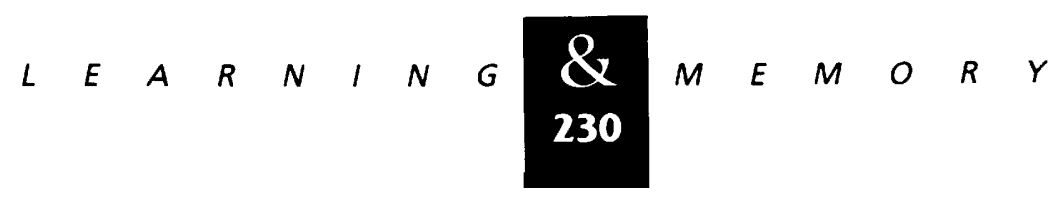


significant but its cause is not clear $(P=0.0003$, using the studentized range test to adjust for multiple contrasts). Relevant trial numbers are listed in Table 1.

The ssr rise to tactical skill began very early in the session for subjects Ju and Bo, but it was delayed for Ge, Le, and very much so for Sc. Those delays included pauses of at least 10 trials during which hardly any effort was made to use or scale the strategy (ssr near zero).
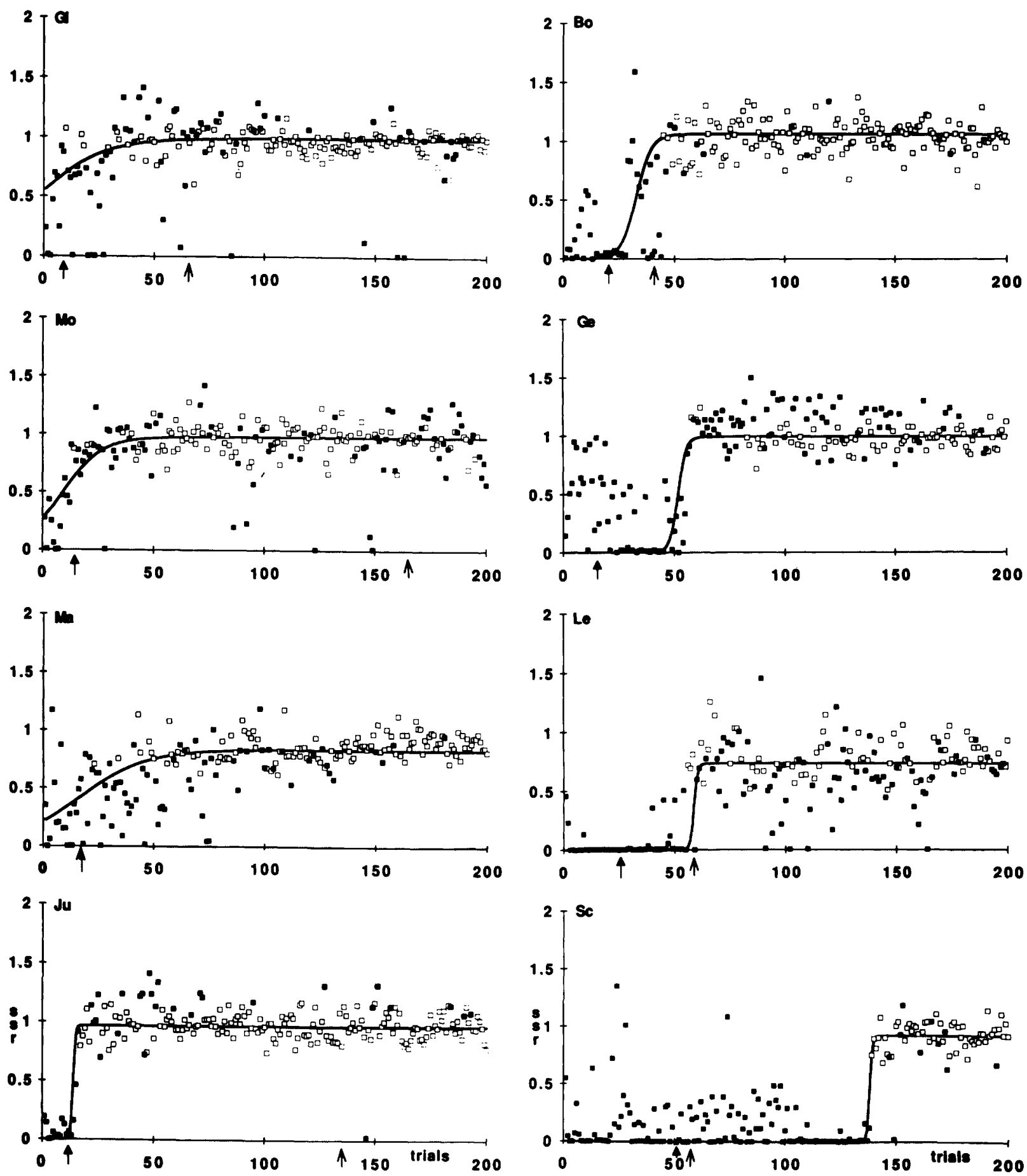

Figure 2: (See facing page for legend.)

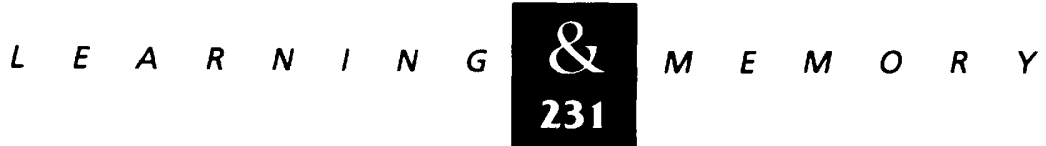




\section{Brooks et al.}

\section{DECLARATIVE KNOWLEDGE}

Subjects' utterances in their first declarations of insight during the learning session are indicated in Figure 2 by arrows below the abscissae and quotes in the legend. Declarations about the correct strategy and tactics were the first unambiguous statements about the need to reverse movement direction, and to do so in the correct time scale. (The need for scaling movement amplitudes appropriately was voiced in the first declaration only by subject Mo). The main result is that strategy declarations were made before those for tactics, except for one declaration that embraced both (subject Ma).

\section{STRATEGY}

In most cases, implicit knowledge of strategy preceded its verbal declaration, and both preceded task success. First declarations of strategy were made before attainment of task success, that is, they were based on knowledge of unsuccessful performance, except for subjects Mo and Sc, who declared strategy knowledge (or "insight") at or after their first success (Table 1, columns 5 and 6). Interestingly, nonsearch subjects also had to acquire verbal, declarative knowledge of what movement patterns to make and how much to scale them, just like search subjects, despite having begun the session with implicit knowledge. Strategy insight was reached after about the same number of trials by nonsearchers and searchers (9-18 vs. 7-24 trials, except for subject Sc at 51). Most often they followed tryouts of repeatedly raised ssr values. Confirming strategy declarations were voiced after one to eight repeated successes (column 7). We noted that verbal responsiveness was loosely related to outside limits of performance but not to its details. Subjects that started their session with the most advanced performance were also most attentive, verbally agile, and precise (Gi, $\mathrm{Ju}$ ), whereas the most delayed sigmoid rise occurred with the least verbal one (Sc; Table 1, columns 2 and 10; Materials and methods).

\section{TACTICS}

First declarations of tactics, unlike those of strategy, depended on actual or imminent achievement of task success (Table 1, columns 5 and 8 ). In the few instances where tactical declarations were delayed toward the end of the session, as for Mo and Ju, intervening comments indicated that the subjects had known it earlier but had not voiced it. All subjects confirmed tactical insight, usually in more detail than at first, after repeated successes, except Ge who made no clear tactical declarations at all (Table 1, column 9). In most cases, task success depended on high ssr values that were achieved during or after the sigmoid rise of movement scaling. As for strategy, implicit knowledge of tactics preceded its verbal declarations (described in Figs. 5 and 6, below).

Figure 2 and Table 1 document that five subjects began the session with a trial-and-error search during which they progressed to specifying the strategy. Three subjects began with sufficient preexisting knowledge to start, instead, with consistent amplitude rescaling that rose along a sigmoid curve during which they declared strategic and tactical insight. Regardless of how subjects began, they first declared strategy insight within the initial 20 trials (Sc was an exception at 51). Implicit knowledge about motor strategy and tactics both developed from the beginning of the learning session, but declarative knowledge about the two was reached at different times. Declarative knowledge of strategy was voiced first because it required only knowledge of performance, whereas that of tactics came later, being linked to impending or actual task success ( $\mathrm{Ma}$ and Sc were exceptions with a joint, or near-joint, declaration). All subjects achieved tactical skill after sigmoid rises with similar durations. The rise of several search subjects began after an intervening period during which the correct strategy had not been used.

Reliability of the learning curves in Figure 2 is buttressed by eight more curves of silent subjects, tested without verbal comments in a preliminary series (Fig. 3). They closely resemble those of the talking subjects in Figure 2. Four subjects (A-D) aligned with the nonsearch group (Table $1,{ }^{*}$ ), and six $(E-J)$ with the search group. The combined data of silent and talking subjects show that the initial trial-and-error phase of seven search subjects was accomplished in 12-136 trials, that is, in $<4-10 \mathrm{~min}$. The sigmoid rise to tactical skill was completed in 5-34 trials by the 11 searchers, and in 45-93 trials by the 7 nonsearchers, that is, in $0.5-3 \mathrm{~min}$ and in $4-8 \mathrm{~min}$.

(Two other silent subjects in Fig. 3 are shown without superimposed curves, as they could not be fitted with the sigmoid model. The reasons were that A performed sufficiently well from the

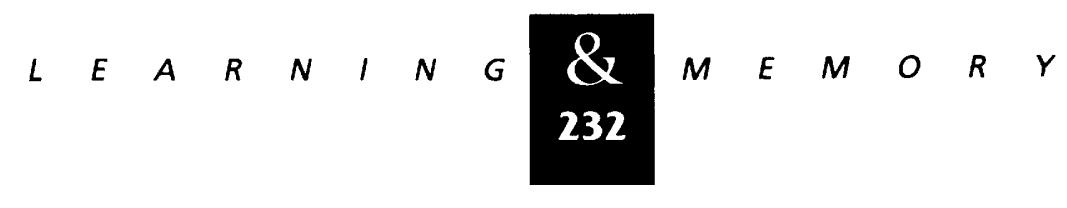



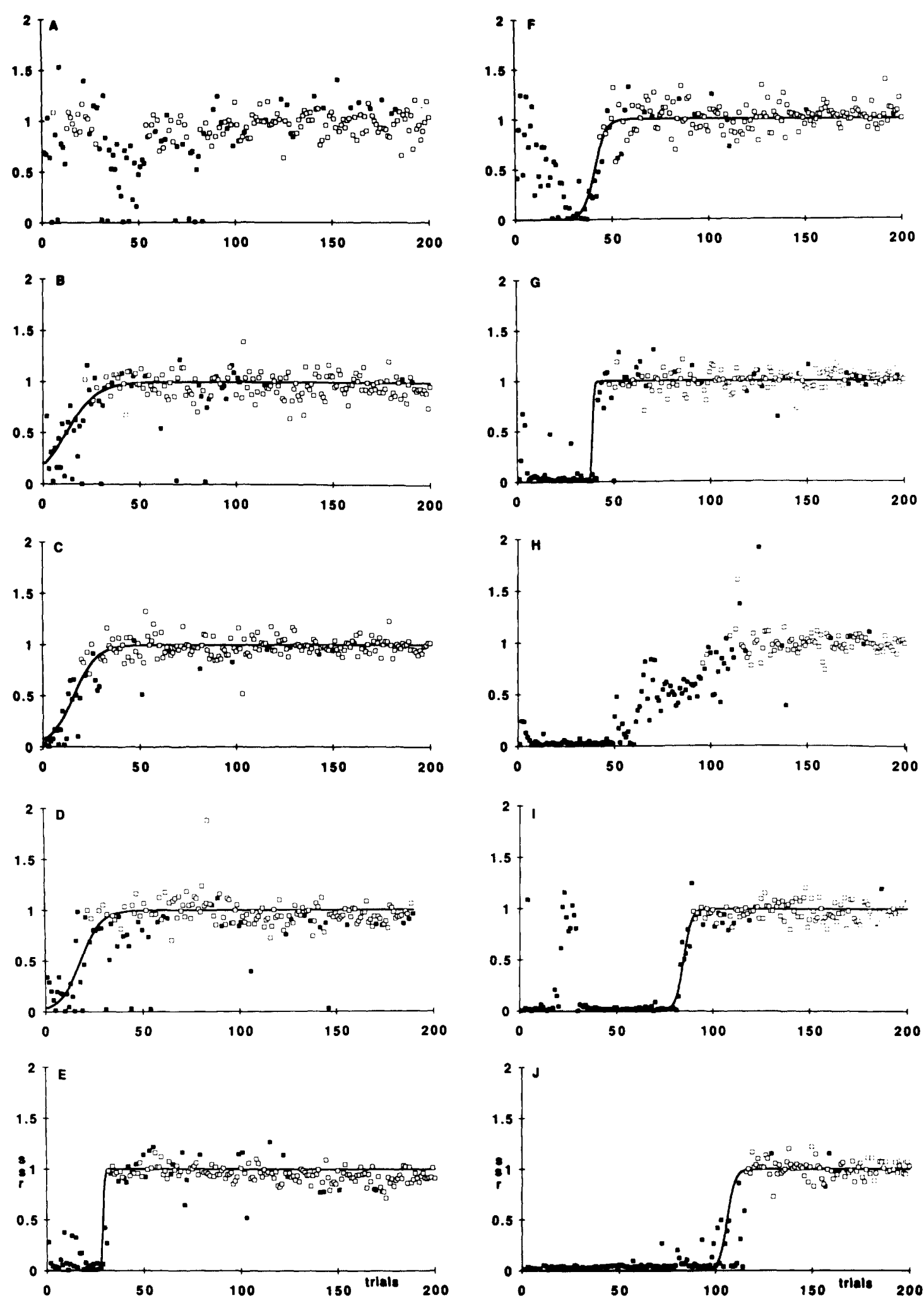

Figure 3: Learning curves of 10 silent subjects $(A-f)$ that were tested without obtaining verbal comments. Curves are ordered by increasing durations of initial trial-and-error search. The first four subjects began consistent scaling along a sigmoid rise without any preceding search. Same conventions as in Fig. 2; trial data are listed in Table 1.

$$
\begin{array}{llllllllllllllll}
\hline & E & A & R & N & I & N & G & \begin{array}{l}
\boldsymbol{Q} \\
\mathbf{2 3 3}
\end{array} & M & E & M & O & R & Y
\end{array}
$$




\section{Brooks et al.}

beginning to exclude a sigmoid rise, and $\mathrm{H}$ progressed oddly, with two ssr-rise episodes starting near trials 50 and 75 , which made the parameters of a single sigmoid fit irrelevant.)

The calculated learning curves of the pooled talking and silent subjects are displayed in Figure 4 . They are one population when judged by the durations of their sigmoid rises $(P=0.106$, and even more if calculated as log transform in the two-way anova). In contrast, however, the pooled search and nonsearch subjects had significantly different sigmoid rise durations $(P<0.001$; respective ranges of 5-34 and 45-93 trials; Table 1, column 3 ). Sigmoid curves for talking subjects leveled off at ssr values of $0.73-1.1$, and all curves for silent ones at 1.0.

\section{DEVELOPMENT OF TACTICAL INSIGHT}

The relation of subjects' self-reports to hand movements and cursor trajectories give more detailed information than was provided in the overview of performance and first declarations (Fig. 2). Changes from implicit to declarative knowledge could be swift, as documented by comments made by Ge and Ma that they did not know what to do or how to stop the cursor, just six and four trials ahead of their verbal strategy insights (Figs. 5A and 6C). Altogether, six subjects made comments about not knowing the tactics (without distinction between search and nonsearch subjects; Gi, Mo, $\mathrm{Ma}, \mathrm{Bo}, \mathrm{Ge}$, and Sc). Ma and Sc were both exceptions, in different ways. Ma gave a uniquely precise specification when to reverse hand movements in terms of cursor distance from the target (trial 57). Sc presented the only instance of evolving conscious, rather than implicit tactical knowledge. His first unambiguous insights into strategy and tactics (trials 51, 56; Fig. 6A) were preceded by increasingly detailed comments about tactics for conscious attempts (trials 20 and 25 , and particularly trials 40 and 45 ). His exceptional success at trial 50 also was an oddity, in that he used very slow movements as a tactical option for implementing the task strategy. The start movement was an exploratory creep forward, made so slowly that an equally slow stop movement just met his brief, final dwell time requirement (uppermost record of Fig. 6B; Materials and methods). However, Sc then failed to get the timing right in the next $\sim 40$ trials despite trying different movement speeds, accompanied by repeated comments to that effect.
Figure 4: Summary of calculated sigmoid curves for search $(A)$ and nonsearch (B) subjects. Solid and dotted lines indicate talking and silent subjects, respectively. Curves are from Figs. 2 and 3.
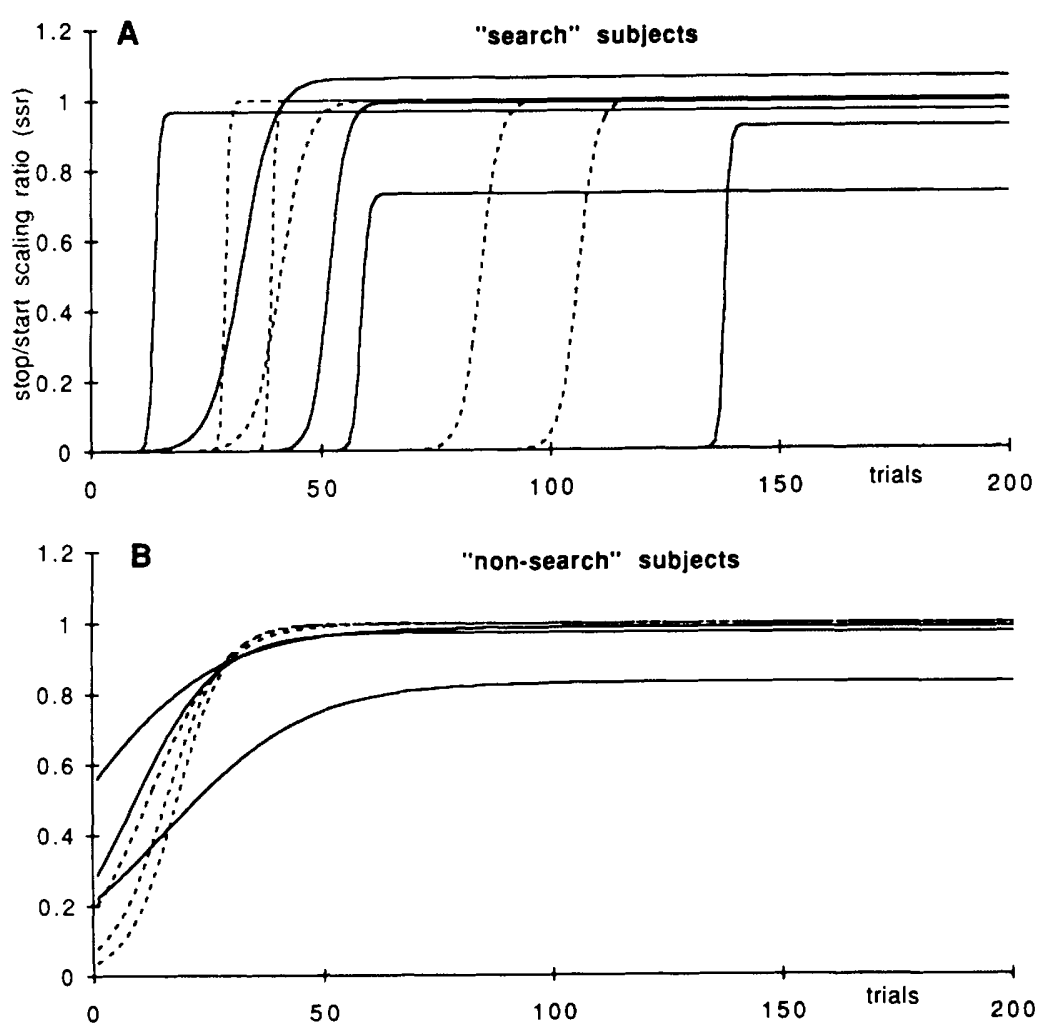


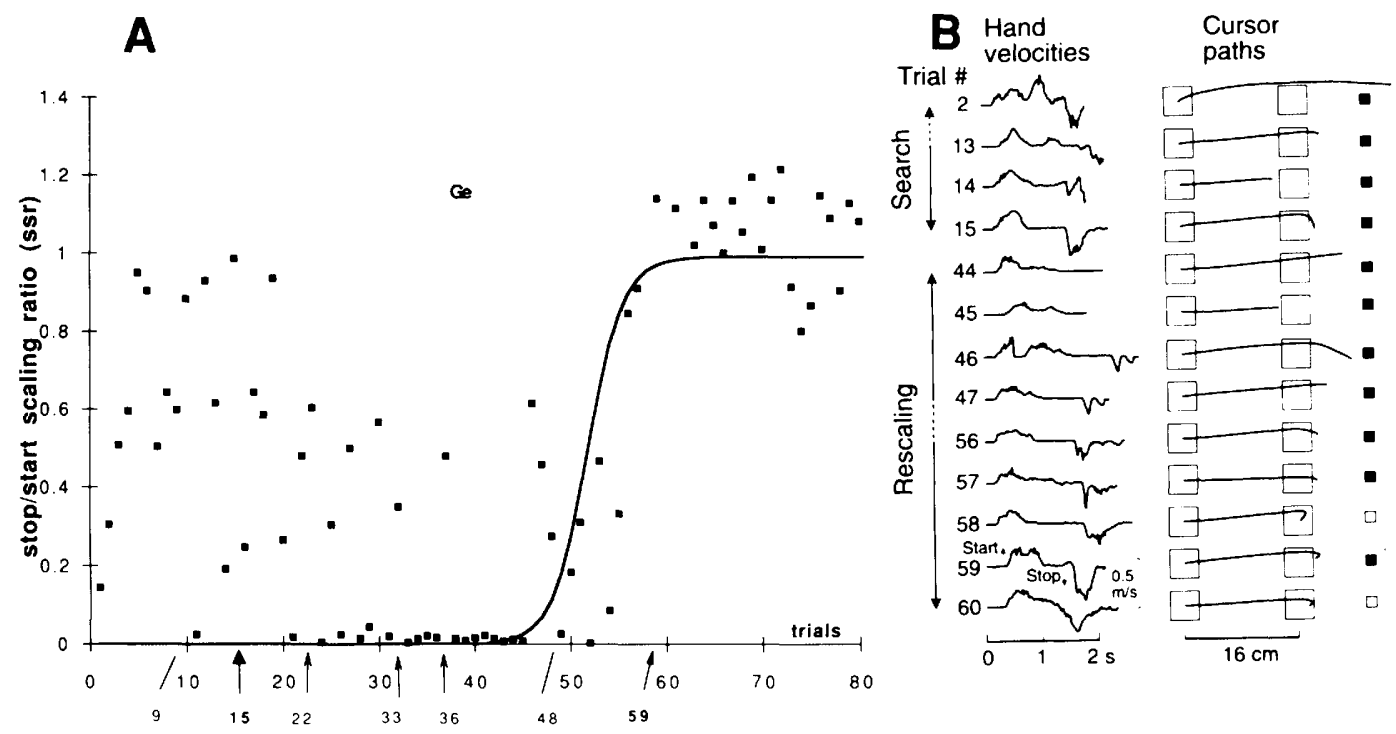

Figure 5: Learning of the rate control task by subject Ge began with initial trial-and-error search for strategy and tactics. (A) Bold numbers on the abscissa and the solid broad arrow denote declaration of strategy insight; narrow arrows signify comments on tactics; the line without an arrowhead denotes comment of uncertainty. Comments at trials: (9) "cannot explain, poor control"; (15) "have to brake and reverse before reaching target"; (22) "if too fast forward, cursor overshoots"; "if too slow, not into target"; (33) "need to make hand movement independent of cursor path"; (36) "once cursor moves, cannot brake or influence it"; (48) "still don't know how it works"; (59) "have to reverse to stop cursor". (B) Velocity profiles of hand movements in single trials, numbered at left, selected to show changes during strategy search and period of rescaling. Start and stop movement profiles up and down. Cursor paths for the same trials at right. Calibrations: velocity bar, $0.5 \mathrm{~m} / \mathrm{sec} ; 2 \mathrm{sec}$ time base; distance between centers of start and target box $16 \mathrm{~cm}$.

The examples for Ge and Sc provide important details about development of tactical knowledge because both experienced periods of not using the strategy (ssr near zero, respectively near trials $30-45$ and $100-138$ ) immediately before onset of the sigmoid rise. Such pauses, also seen for Le and for silent subjects $G-J$, provide evidence that the rapid sigmoid upscaling of the ssr could rest on memory of unsuccesful trials before the pause.

\section{SKILL ACQUISITION DURING THE SIGMOID RISE}

Movements made during the upper part of the sigmoid rise of amplitude scaling expressed distinct tactical options to achieve task success. Particularly obvious changes are demonstrated in Figures $5 \mathrm{~B}$ and $6 \mathrm{~B}$. Start movements were opposed by increasingly well-timed stop movements with ever more suitable amplitudes, rise times, and durations (e.g., Ge, from trial 46 on; Sc, from trial 139). Near the top of the sigmoid, when subjects mastered the final dwell period in target, stop movements also reached higher peak velocities than the start movements preceding them. As well, that period of consistent rescaling toward task success was marked by increasingly smooth velocity rises, with the fewest corrections, for start movements and particularly for stop movements (e.g., Ge, trials 58-60; Sc, trials 139-142 and thereafter).

These special aspects of movement scaling yielded success (accompanied by declarations of tactical insight), but scaling in that manner did not necessarily persist. For instance, after Sc had confirmed his visuomotor tactics during the first of a series of sustained successes (trial 140), he reverted to making start movements of more moderate speed that remained successful as long as the stop movements were made fast enough (after trial 178). Such regression to the more usual tactical option of moderate speed was most obvious in this instance, but it was noted for most subjects. After sigmoids had leveled off, $\mathrm{Gi}, \mathrm{Mo}, \mathrm{Ma}$, and Bo also regularly made start movements of moderate speed that were followed by faster stop movements. This stable mode of performance coincided with expressions of confidence in being successful. For instance, at trial 193 Sc said, "It always works when I use the same technique"; at trial 180 Gi said, "It still works, all depends on how well

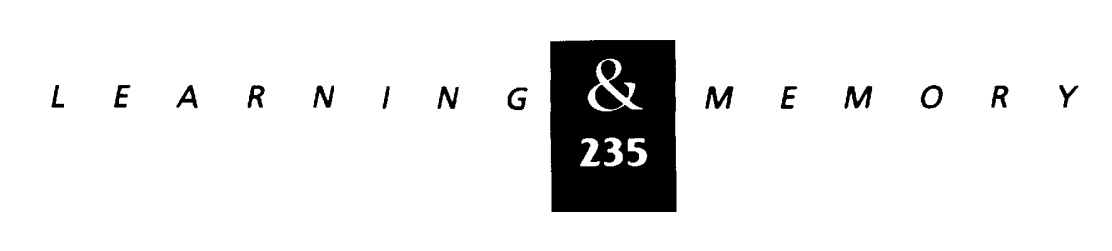




\section{Brooks et al.}

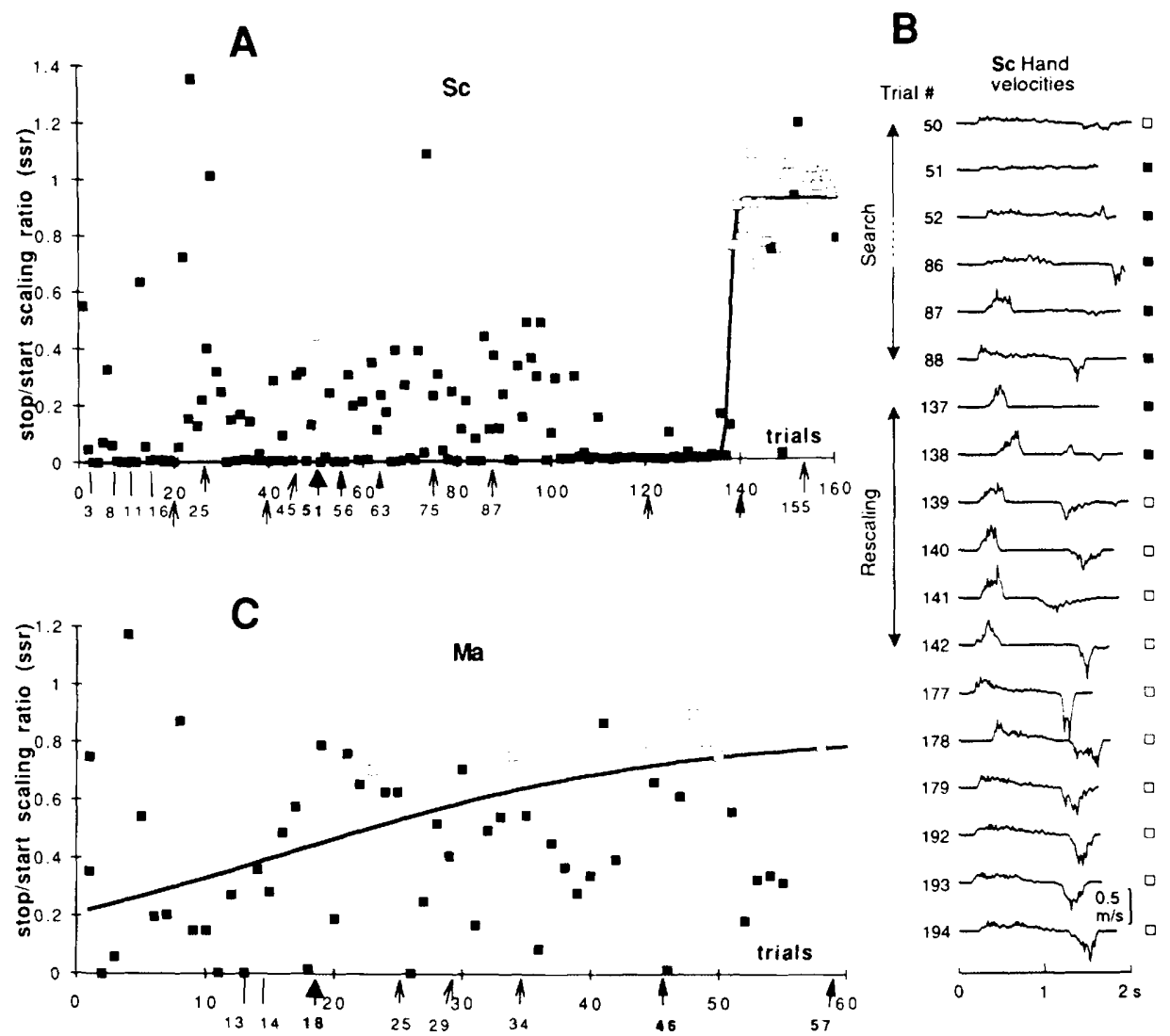

Figure 6: Implicit trial-and-error learning yields declarative knowledge about strategy, followed by that about implementing tactics. Open arrows indicate other tactical comments. Plots are for subjects Sc and Ma; data are from the early part of sessions. Conventions are as in Fig. 5. (A) Plot of ssr values; (B) selected velocity traces of Sc. Comments of Sc at trials: (3) "it's not logical"; (8) "I cannot understand"; (11) "don't understand"; (16) "don't understand"; (20) "I am really trying!"; (25) "strange, I cannot do it!"; (40) "can one haul it back in time?"; (45) "oh!" [nearly right]; (51) "aha! you have to reverse"; (56) "have to move within the right time and then brake"; $(63)^{\prime \prime}$. . and to hold for the right time" ; (75) "trying some different speeds"; (87) "what matters is to go to that special point and return the same distance"; $(120)$ "still trying different speeds"; (140) "brake by pulling pen back when I get near target"; (155) "have to gauge both forward and backward speeds correctly"; (178) "go there and pull back quickly, as I thought"; (193) "it always works when I use the same technique." (C) Plot of ssr values of Ma. Comments of Ma at trials: (13) "no ideas yet"; (14) "don't know what controls cursor"; (18) "steer to target and reverse when I approach target"; (25) "I am getting it under control now"; (29) "it's hard"; (34) "goes too fast, not long enough?"; (46) "Have to reverse to brake"; (57) "start braking $\sim 1 \mathrm{~cm}$ ahead of target." Plot conventions are as in Fig. 2.

one makes return movement"; at trial 166 Mo said, "Always go the same distance along that line"; at trial 132 Ma said, "I am now confident about doing it right"; and at trial 72 Bo said, "I really don't have to think about it any more."

Yet, tactics continued to change after the initial learning session. After many sessions, individuals became overtrained and acquired even greater skills, such as predetermining wrist postures at the end of start and stop movements. Their hand movements then exhibited the well-known single-peaked, predictive velocity profiles (as in Fig. 1).
Strategy learning began implicitly but soon was accompanied by conscious verbal groping for clarity until subjects voiced unambiguous declarations of insight. In contrast, comments about tactics made before subjects' first declaration of tactical insight showed that learning of tactics was entirely implicit, including the beginning of the sigmoid rise to tactical skill (with the exception of Sc). Movements changed in a distinct manner when the rise of amplitude scaling was well under way. Start movements were opposed earlier by stop movements of adequate amplitudes. Near the top of the sigmoid, they reached higher peak ve- 
locities than the start movements preceding them. Also, in the upper part of the sigmoid rise, when subjects mastered the final dwell period in target, consistent rescaling toward task success was marked by increasingly smooth velocity rises, with the fewest corrections, for start movements and particularly for stop movements. Thereafter, most subjects continued successfully most of the time, although they returned to using movements with lower peak velocities and accelerations. After the first declaration of tactical insight, subjects' comments on tactical improvement could continue to the end of the session, although the majority expressed confidence in the successful routines that they had adopted.

\section{FAILURE TO LEARN}

Seven additional subjects to those presented in Figures 2 and 3 failed to learn the task, of which four belong in the talking group and three in the silent group. The ssr values of their sessions are plotted in Figure 7 . The failures demonstrate the weakness of isolated strategic insights without concurrent tactical support. Two of the talkers declared the need for oppositely directed movements, but only one reached successful strategy use even transiently (in two trials). The other two talkers never emerged from unsuccessful trial-anderror attempts. Their comments suggest that one important cause of their failure was their inability
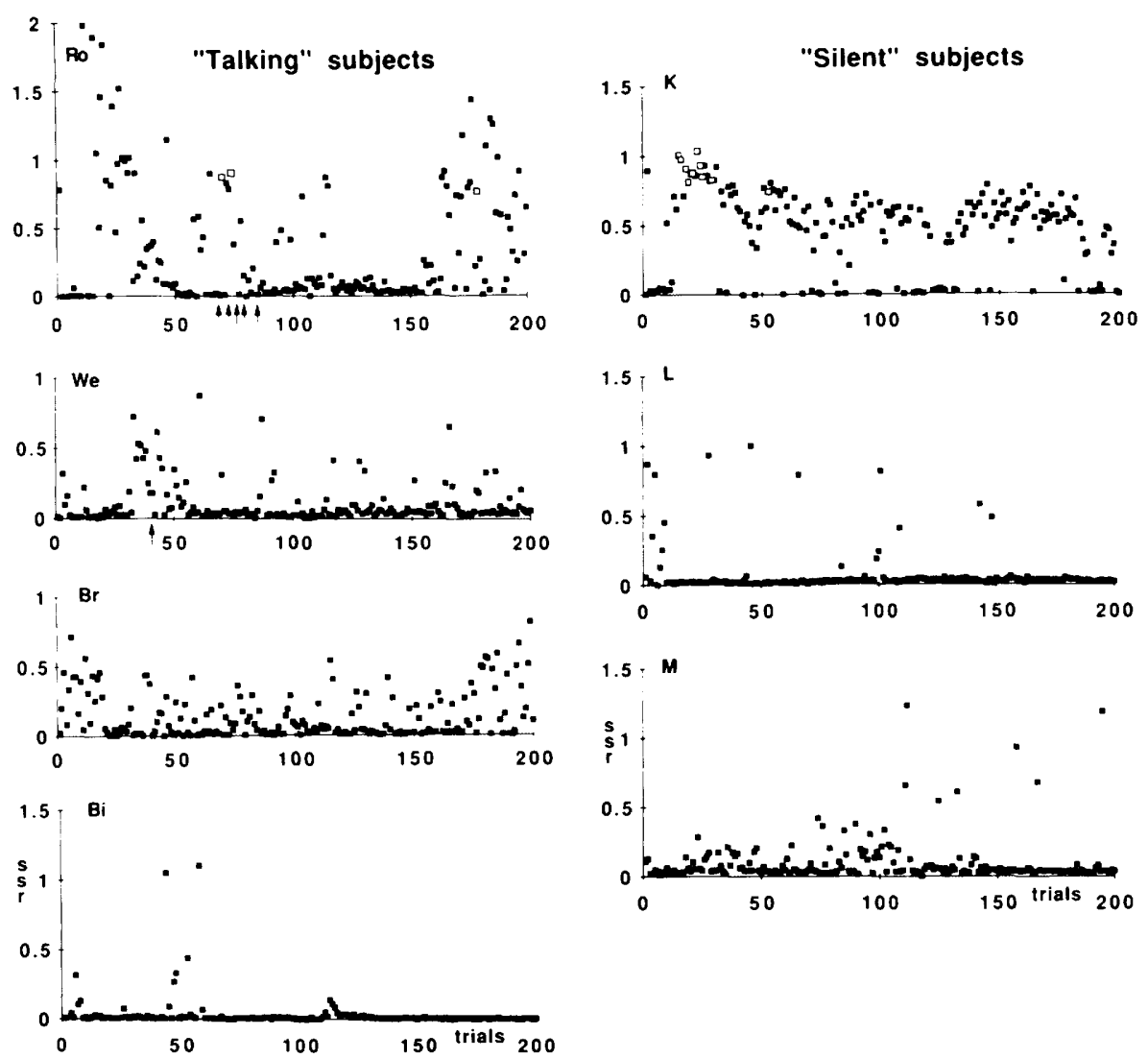

Figure 7: Learning attempts of seven subjects who failed to learn the task successfully. (Left) Talking subjects (Ro, We, $\mathrm{Br}, \mathrm{Bi}$ ); (right) silent subjects K, L, M. Comments at trials: (Ro) Trial 70, "now I have it!"; (72) "ah yes!"; (74) "now I understand"; (76) "I have to go forward and backward"; (85) "I have to come back". (We) Trial 20, "Seems to have something to do with acceleration or velocity"; (28) "have to see if I can stop it"; (45) "seems to depend on reversing". (Br) Trial 9, "I should go more slowly"; (40) "doesn't work if one reverses"; (55) "try a little faster"; (71) "too slow"; (72) "too fast"; (80) "I am still thinking about velocity"; (170) "still not far enough"; (Bi) Trial 4, "cursor seems to be delayed, not like normal movements"; (47) "should do something different but I don't know what"; (54) "I am trying to just do it instead of thinking about it"; (127) "this may not be possible at all." Same conventions as in Figs. 2 and 3.

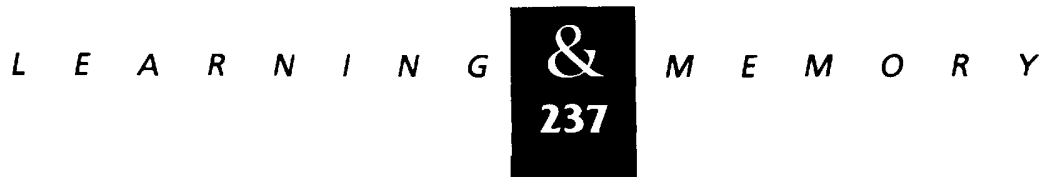


Brooks et al.

to scale movement timing as well as that of amplitudes. The silent group included $\mathrm{K}$ who rescaled consistently at the beginning of the session and did achieve nine clustered successes but failed thereafter because scaling of amplitudes was not matched by that of timing. The other two, $L$ and $M$, failed badly and could not fathom the task.

\section{Discussion}

This study addressed the development of declarative knowledge of motor strategy and tactics by normal human subjects while learning an unfamiliar step-tracking task that involved rate control. The main new finding was that for all but one subject, strategy knowledge became verbally declarative from knowledge of unsuccessful performance (cf. Gentile 1972), whereas tactical knowledge depended on skill sufficient for task success. Subjects' ubiquitous and unsuccessful use of the correct strategy early in the learning session probably rested on transfer of implicit knowledge of rate control from some previous experience. This might have been acquired from computer games or through common actions like driving a car where speed is governed by two oppositely directed foot movements, acceleration by ankle extension to depress the gas pedal, and deceleration by ankle flexion that allows road friction to slow the car.

The time course of learning in the present task involved several seconds between trials and several minutes for acquiring tactical skill, which is comparable to that in serial reaction time tests (Nissen and Bullemer 1987). In those tests, subjects used motor strategies that they already knew from previous practice; no new combinations of movements were called for. Typical test strategies were pressing four keys with two fingers of each hand (Nissen and Bullemer 1987; Willingham et al. 1989), using four fingers of one hand (Sanes et al. 1990; Pascual-Leone et al. 1994), or performing other previously practiced motor actions such as pointing, reaching, or various hand postures. These tasks share features with ours, such as emphasis on accuracy rather than speed, trial repetition rate, and rate of learning; but their subjects did not have to devise motor strategies and tactics as we have defined them.

Our results confirm that declarative (explicit) and implicit knowledge can develop at the same time (e.g., Nissen and Bullemer 1987, Willingham et al. 1989; Sanes et al. 1990), which is not to deny that they also can occur independently of each other (Willingham et al. 1989; Stadler 1993).

\section{IMPLICIT KNOWLEDGE}

During trial-and-error search, our subjects generated the correct movement sequence, although some stated at that time that they did not know what to do or how to control the cursor. The same was true during the sigmoid rise of the movement scaling ratio to tactical skill. Verbal selfreports, when given, denied knowledge of correct performance until imminent or actual task success (when the ratio approached its highest level). This was also true for nonsearch subjects that began the session with a consistent sigmoid rise, which probably reflects firmer transfer from previous experience with some form of rate control than that experienced by search subjects.

\section{DECLARATIVE KNOWLEDGE}

Strategic knowledge was first declared during trial-and-error learning, often after unsuccessful tryouts of using the correct strategy in a few successive trials during which scaling of stop movement amplitudes improved (Figs. 5 and 6). It seems possible that these first declarations were based on insight through extrapolation from shortterm memory of the trend generated during the tryouts. Onset of the sigmoid rise of tactical skill is also likely to have incorporated short-term memory of such trends, particularly when the rise began immediately after periods of hardly using the strategy (ssr near zero; e.g., Fig. 2, Ge, Le, Sc; Fig. 3, also G-J).

Quantitative differences also bear on the different learning rates for strategy and tactics because a few items are learned more quickly and remembered better than a longer string (e.g., Willingham et al. 1989; Pascual-Leone et al. 1993). In this study strategy insight consisted of just one item: to make sequential, oppositely directed movements, whereas tactical insight encompassed two items: scaling of movement amplitudes and of their timing. Strategy learning was also found to be faster than learning the tactics when subjects traced a pattern display (Sanes et al. 1990). When switching from normal to mirror-reversed vision they changed strategy in $<10$ trials, which was five

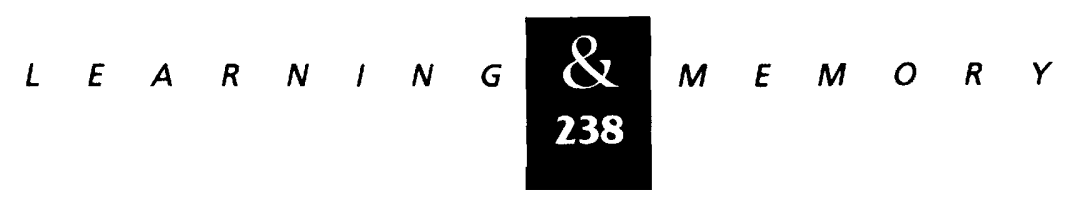


times faster than the time needed to gain optimal response times.

\section{DEFINITIONS OF STRATEGY}

Our present strategy definition, "what pattern of serial movements to make," evolved from the more general ones of making "predictive" movements (Brooks 1979) that expressed intention by being emitted with reaction times (Houk 1978); and "what to do" ("insightful" learning, Brooks 1986, 1990a,b; Brooks et al. 1992, 1994). The current study was triggered by two others that described distinct learning phases. In one, monkeys learned a step-tracking task that required the strategy of making a single elbow movement followed by a dwell period in target (Brooks et al. 1983); and in another where monkeys learned to press on a lever until cued to release it in response to a visual signal (Sasaki and Gemba 1983). An abrupt change of performance was noted during learning of both tasks. In the step-tracking task, selection of the move-and-hold pattern was accompanied by abandonment of movements with multipeaked velocity profiles and adoption of single-peaked movements (much as in Fig. 1); in the lever-release task there was a sudden shortening of reaction times. These kinematic and chronometric predictive indicators coincided for the step-tracking task (Fig. 6; Brooks 1986), showing that strategy insight for intended single-joint movements was expressed by their shortened reaction times as well as by single-peaked velocity profiles. Sasaki and Gemba (1991) have since referred to the two phases as recognition learning and skill learning.

The definition of strategy had another beginning in the consideration of postural movements. Strategies were described as reaction-time processes for the sequential use of the hip and ankle joints to keep the body's center of gravity between the legs (for human or for quadruped stance; Nashner and McCollum 1985; Horak and Nashner 1986; Macpherson 1988, 1991). Tactics were the appropriate muscle synergies to exert the required torques (Nashner and Grimm 1978). These implicit strategies have been discussed by Buchanan et al. (1990) and Windhorst (1991).

\section{OPTIMAL TACTICAL COMPOSITION OF MOVEMENTS}

Single-peaked velocity profiles were rare in the present study because our paradigm allowed enough time for movements of moderate speed (with several acceleration zero crossings, Brooks et al. 1973; Polit and Bizzi 1979). Only overtrained subjects made consistent use of fast, single-peaked movements (Fig. 1) as has been reported for monkeys (Fig. 5; Brooks and Watts 1988; Brooks 1990b). Sanes et al. (1990) reported limitations similar to ours for relating single-peaked velocity profiles to declarative knowledge for subjects that were learning mirror writing.

Multipeaked velocity profiles were also observed as the rule for monkeys that were just learning a step-tracking task (cf. Brooks et al. 1983), as well as for trained monkeys who had to adapt when the distance to target suddenly became uncertain because the target display and auditory cues were temporarily withdrawn (Kozlovskaya et al. 1974). Similar decomposition of single-peaked movements into multipeaked ones was also reported by Ojakangas and Ebner (1991), when they changed the distance to target unexpectedly for monkeys performing a step-tracking task.

\section{CONSIDERATION OF NEURAL PATHWAYS}

Search for successful strategy and tactics in the present work involved comparison of trials separated by only a few seconds or minutes. These comparisons probably rested on short-term, representational memory (Goldman-Rakic 1987) that is supported by the prefrontal-parietal system. Its corticocortical connections include nonprimary motor areas, such as the medial and lateral premotor area 6 (SMA, PMA), which are connected, with the basal ganglia and cerebellum as well as with the primary motor area (M1). The cerebellum is the most likely candidate for supporting the sigmoid rise of movement scaling because it is thought to assist learning by composing intended movements and storing their information (Brooks and Thach 1981; Thach et al. 1992; also see Halsband and Freund 1993). An additional candidate is the basal ganglia (Mishkin 1979; Passingham 1993), which are thought to enable the cooperation and sequencing of movements, postures, and the various motor programs that are active at the time (Mink and Thach 1991).

The sigmoid rise is the key period for sequencing properly scaled move and hold periods. Its time scale is in the range of that of cerebellar scaling. Thach et al. (1992) reported that subjects

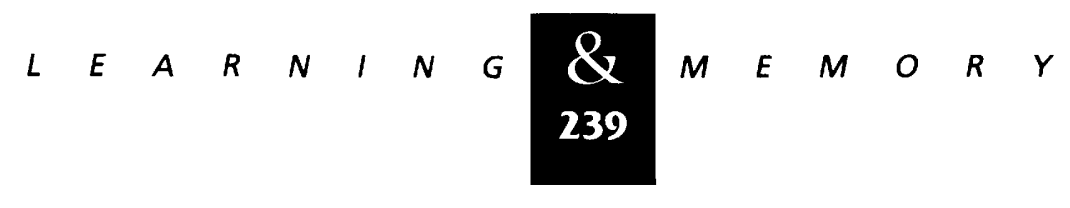


rescaled arm movements for accurate pointing or throwing an object at a target to double their initial accuracy in $\sim 10-20$ trials and to optimum in about 50 trials. Support by the cerebellum was proved by the inability of patients to recalibrate their accuracy if they had lesions of the olivary input to the cerebellum (Weiner et al. 1983; Thach et al. 1992). Patients with cerebellar atrophy also learned less well than normal subjects to accurately trace prescribed patterns with hand movements (Sanes et al. 1990). The time course of the sigmoid rise is also on the order of that needed by subjects for composing appropriate muscle synergies with the right timing to regain steady stance after perturbations, which cerebellar patients could not accomplish (Nashner and Grimm 1978).

The basal ganglia might be particularly involved in the final part of the sigmoid rise because that is when subjects got the time scale right for the final dwell period in target. The final part of the rise to skill is stressed because Kawashima et al. (1994) found a special basal ganglia activation during the final skill learning of a pointing task. They examined M1, SMA, and PMA of subjects learning to scale sequential pointing movements, using positron emission tomography (PET) to image regional cerebral blood flow ( $\mathrm{rCBF}$ ). After preliminary learning of the positions of seven targets, subjects learned particularly accurate pointing in seven to eight additional trials, where fields in M1 and PMA became especially active; but most im. portantly for this discussion, an additional field in SMA became active during the final stage of preparing to point. Kawashima et al. (1994) suggested that this SMA field, and thus possibly the basal ganglia, could serve visuomotor transformations as an internal reference for moving.

Both PMA and SMA probably cooperate in improving performance during learning. Their projections to $M 1$ could have contributed to changes in M1 during motor learning that were demonstrated by Pascual-Leone et al. (1994) by mapping cortical motor fields activated with focal transcranial magnetic stimulation. Until subjects' declarative knowledge was established (by generating learned special sequences of sequential finger movements), motor fields of muscles in M1 enlarged, after which they returned to their baseline values. In another study by Jenkins et al. (1994), subjects' trial-and-error learning of sequential key presses in a serial reaction time test revealed activation of the prefrontal and parietal association cortex, PMA, cerebellum, and putamen. Changes of brain function were measured by rCBF with PET.

\section{Acknowledgments}

Programs for the test and for data acquisition were written by Uirich Longerich and Uwe Knorr, for data analysis by Martin Brooks, and for robust sigmoid curve fitting by Pierre Boulanger. This work was supported in part by the Deutsche Forschungsgemeinschaft (SFB 200 B3). We thank Carolee Winstein for helpful discussions.

The publication costs of this article were defrayed in part by payment of page charges. This article must therefore be hereby marked "advertisement" in accordance with 18 USC section 1734 solely to indicate this fact.

\section{References}

Brooks, V.B. 1979. Motor programs revisited. In Posture and movement (ed. R.E. Talbott and D.R. Humphrey), pp. 13-49. Raven Press, New York.

1986. How does the limbic system assist motor learning? A limbic comparator hypothesis. Brain Behav. Evol. 29: $29-53$.

1990a. Limbic assistance in task-related use of motor skill. The principles and design operation the brain. Pontif. Acad. Sci. Scr. Varia 78: 343-364. lalso published as Exp. Brain Res. (Supplement) 21].

1990b. Adaptation and learning of arm movements. In From neuron to action (ed. L. Deecke, J.C. Eccles, and V.B. Mountcastle), pp. 3-12. Springer Verlag, Berlin, Germany.

Brooks, V.B. and S.L. Watts. 1988. Adaptive programming of arm movements. I. Motor Behav. 20: 117-132.

Brooks, V.B. and W.T. Thach. 1981. Cerebellar control of posture and movements. In Motor control, Handbook of Physiology. The Nervous System (ed. V.B. Brooks), Vol. 2, pp. 877-946. American Physiological Society, Bethesda, MD.

Brooks, V.B., J.D. Cooke, and J.S. Thomas. 1973. The continuity of movements. In Control of posture and locomotion (ed. R.B. Stein, K.R. Pearson, R.S. Smith, and J.B. Redford.), pp. 257-272. Plenum Press, New York.

Brooks, V.B., P.R. Kennedy, and H.-G. Ross. 1983. Movement programming depends on understanding of behavioral requirements. Physiol. Behav. 31: 561-563.

Brooks, V.B., F. Hilperath, H.-G. Ross, M. Brooks, and H.-J. Freund. 1992. Strategy selection triggers movement scaling. Soc. Neurosci. Abstr. 18: 1551.

Brooks, V.B., F. Hilperath, and M. Brooks. 1994 Strategy probing, verbal declaration of insight, and tactical movement control. Soc. Neurosci. Abstr. 20: 334.

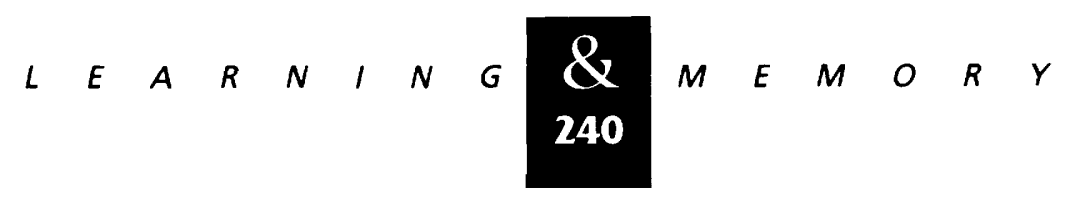


Buchanan, T.S., G.P. Rovai, and Z.W. Rymer. 1990. Strategies for muscle activation during isometric torque generation at the human elbow. I. Neurophysiol. 62: $1201-1212$.

Gentile, A. 1972. A working model of skill acquisition with application to teaching. Quest 17: 3-23.

Goldman-Rakic, P.S. 1987. Circuitry of primate prefrontal cortex and regulation of behavior by representational memory. In Higher functions of the brain. Handbook of physiology (ed. F. Plum), Vol. 5, pp. 373-417. American Physiological Society, Bethesda, MD.

Gottlieb, G.L., D.M. Corcos, and G.C. Agarwal. 1989. Strategies for the control of voluntary movements with one degree of freedom. Brain Behav. Sci. 12: 189-250.

Halsband, U. and H.-J. Freund. 1993. Motor learning. Curr. Opin. Neurobiol. 3: 940-949.

Horak, F.B. and L.M. Nashner. 1986. Central programming of postural movements: Adaptation to altered support-surface configurations. J. Neurophysiol. 55: 1369-1381.

Houk, J.C. 1978. Participation of reflex mechanisms and reaction-time processes in the compensatory adjustments to mechanical disturbances. Cerebral motor control in man: Long-loop mechanisms. Progr. Clin. Neurophysiol. 4: 193-215.

Jenkins, I.H., D.B. Brooks, P.D. Nixon, R.S.J. Frakowiak, and R.E. Passingham. 1994. Motor sequence learning: A study with positron emission tomography. I. Neurosci. 14: 3775-3790.

Kawashima, R., P.E. Roland, and B.T. O'Sullivan. 1994. Fields in human motor areas involved in preparation for reaching, actual reaching, and visuomotor learning: a positron emission tomography study. J. Neurosci. 14: 3462-3474.

Kim, W.S., F. Tendick, S.R. Ellis, and L.W. Stark. 1987. A comparison of position and rate control for telemanipulations with consideration of manipulator system dynamics. IEEE /. Robot. Automat. RA 3: 426-436.

Kozlovskaya, I.B., A. Atkin, F.E. Horvath, J.S. Thomas, and V.B. Brooks. 1974. Preprogrammed and feedback-guided movements of monkeys. Behav. Biol. 12: 243-248.

Macpherson, J.M. 1988. Strategies that simplify the control of quadrupedal stance. II. Electromyographic activity. I. Neurophysiol. 60: 218-231.

1991. How flexible are muscle synergies? In Motor control: Concepts and issues. Life Sciences Research Report 50 (ed. D.R. Humphrey and H.-J. Freund), pp. 33-47. John Wiley, New York.

Merikle, P.M. and E.M. Reingold. 1992. Measuring unconscious perceptual processes. In Perception without awareness: Cognitive, clinical, and social perspectives (ed.
R.F. Bornstein and T.S. Pittman), pp. 55-80. Guildford Publications, New York.

Mink, J.W. and W.T. Thach. 1991. Basal ganglia motor control. III. Pallidal ablation: Normal reaction time, muscle cocontraction, and slow movemerit. I. Neurophysiol. 65: $330-351$.

Mishkin, M. 1982. A memory system in the monkey. Phil. Trans. R. Soc. Lond. B. 298: 85-95.

Nashner, L.M. and R.J. Grimm. 1978. Analysis of multiloop dyscontrols in standing cerebellar patients. In Cerebral motor control in man: Long loop mechanisms (ed. J.E. Desmedt), Progr. Clin. Neurophysiol. 4: 300-319, Karger, Basel.

Nashner, L.M. and G. McCollum. 1985. The organization of human postural movements: a formal basis and experimental synthesis. Behav. Brain Sci. 8: 135-172.

Newell, K. 1991. Motor skill acquisition. Annu. Rev. Psychol. 42: 213-237.

1985. Coordination, control, and skill. Differing perspectives in motor learning, memory, and control. Adv. Psychol. 27: 295-317. The Netherlands.

Nissen, M.J. and P. Bullemer. 1987. Attentional requirements of learning: Evidence from performance measures. Cognit. Psychol. 19: 1-32.

Ojakangas, C.L. and T.J. Ebner. 1991. Scaling of the metrics of visually guided arm movements during motor learning in primates. Exp. Brain Res. 85: 314-323.

Pascual-Leone, A., J. Grafman, K. Clark, M. Stewart, S. Masaquoi, J.S. Lou, and M. Hallett. 1993. Procedural learning in Parkinson's disease and cerebellar degeneration. Ann. Neurol. 34: 594-602.

Pascual-Leone, A., J. Grafman, and M. Hallett. 1994. Modulation of cortical motor output maps during development of implicit and explicit knowledge. Science 263: 1287-1289.

Passingham, R. 1993. The frontal lobes and voluntary action. Oxford Psychology Series 21. Oxford University Press, New York.

Polit, A. and E. Bizzi. 1979. Characteristics of motor programs underlying arm movements in monkeys. I. Neurophysiol. 42: 183-194.

Rousseeuw, P.J. and A.M. Leroy. 1987. Robust regression and outlier detection. John Wiley, New York.

Sanes, J.N., B. Dimitrov, and M. Hallett. 1990. Motor learning in patients with cerebellar dysfunction. Brain 113: $103-120$.

Sasaki, K. and H. Gemba. 1983. Learning of fast and stable hand movement and cerebro-cerebellar interactions in the monkey. Brain Res. 277: 41-46.

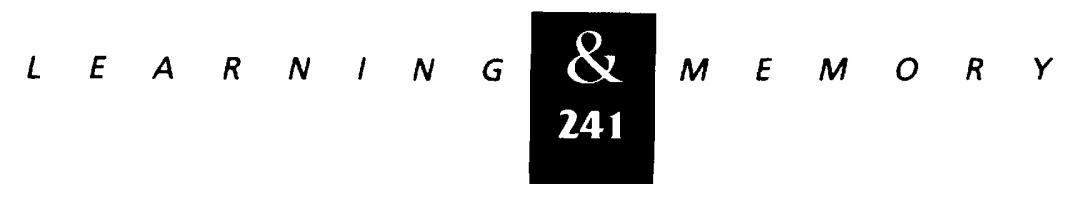




\section{Brooks et al.}

1991. How do the different cortical motor areas contribute to motor learning and compensation following brain dysfunction? In Motor control: Concepts and issues (ed. D.R. Humphrey and H.-J. Freund), pp. 445-461. John Wiley, Chichester, UK.

Squire, L.R. and S. Zola-Morgan. 1988 Memory: Brain systems and behavior. Trends Neurosci. 11: 170-175.

Stadler, M. A. 1993. Implicit serial learning: questions inspired by Hebb 1961. Memory Cognit. 21: 819-827.

Thach, W. T., H.P. Goodkin, and J.G. Keating. 1992. The cerebellum and the adaptive coordination of movement.

Annu. Rev. Neurosci. 15: 403-442.

Weiner, M., M. Hallett, and H.H. Funkenstein. 1983.

Adaptation to lateral displacement of vision in patients with lesions of the central nervous system. Neurology

33: 766-772.

Willingham, D.B., M.J. Nissen, and P. Bullemer. 1989. On the development of procedural knowledge. J. Exp. Psychol. Learning, Memory, Cognit. 15: 1047-1060.

Windhorst, U.R. 1991. What are the output units of motor behavior and how are they controlled? In Motor control: Concepts and issues (ed. D.R. Humphrey and H.-J. Freund), pp. 101-119. John Wiley, Chichester, UK.

Zola-Morgan, S. and L.R. Squire. 1993. Neuroanatomy of memory. Annu. Rev. Neurosci. 16: 547-563.

Received July 11, 1995; accepted in revised form October 16, 1995. 


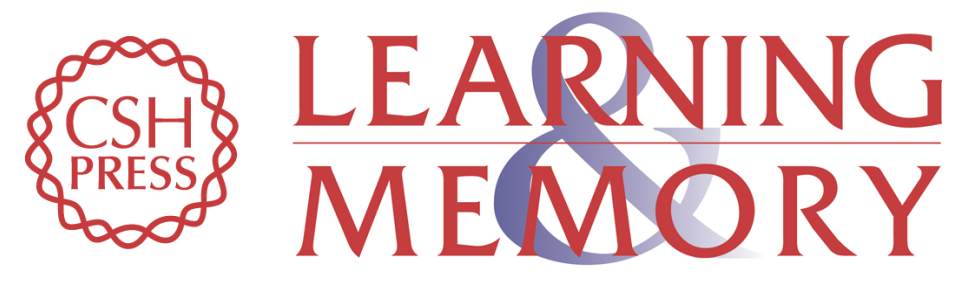

\section{Learning "what" and "how" in a human motor task.}

V Brooks, F Hilperath, M Brooks, et al.

Learn. Mem. 1995, 2:

Access the most recent version at doi:10.1101//m.2.5.225

References This article cites 35 articles, 4 of which can be accessed free at: http://learnmem.cshlp.org/content/2/5/225.full.html\#ref-list-1

License

Email Alerting Receive free email alerts when new articles cite this article - sign up in the box at the Service top right corner of the article or click here. 